\title{
Development of Teachers' Professional Identity as a Second Career in the M.Teach Program as a Lever to Empower the Future Education System
}

\author{
Eitan Simon ${ }^{1}$ \\ ${ }^{1}$ Tel hai Academic College, Israel \\ Correspondence: Eitan Simon, Tel Hai College, Israel.
}

Received: May 6, 2021

Accepted: December 16, 2021

Online Published: January 6, 2022

doi:10.5539/jel.v11n2p35

URL: https://doi.org/10.5539/jel.v11n2p35

\begin{abstract}
The Dovrat Committee (2004) in Israel, pointed up the need for radical change in teacher training programs and recommended introducing school reform programs, such as the New Horizons and the Courage to Change reforms, implemented in the Israeli education system over recent years. The article reviews future teachers' needs that necessitate changes in the education provided by teacher training colleges. It describes research examining teachers' professional identity development and desirable characteristics for the future teacher. Participants were 23 student-teachers studying in an M.Teach degree course. The research investigated their attitudes and perceptions concerning the image of the future teacher.
\end{abstract}

Keywords: teacher training, future teacher, 21st-century skills, technology-assisted teaching, distance teaching, teachers' professional identity, second career

\section{Introdution}

In the 21 st century, education ministries need skills adapted to a dynamic reality of continuous innovation and development. To be able to meet these demands, teacher education should meet high standards, including mastery of multidisciplinary academic knowledge about education, professional expertise, and the use of novel pedagogy and the most sophisticated technology to provide meaningful learning.

Studies and surveys indicate that in order to improve the education system, it is necessary to continually foster teachers' teaching and pedagogic leadership. Understanding this need in Israel, the Dovrat Committee Recommendations (2004) proposed the introduction of school reform programs, such as New Horizons and Courage to Change, which were applied in the Israeli education system in recent years. Today, it is clear that one of the Ministry of Education's priority goals is to empower teachers.

To develop appropriate teacher training programs for this goal, programs should be flexible enough to keep up with the constant social. political and economic changes of today's society. Thus, coherent programs should also consider the political and historical contexts of education in their societies (Richmond et al., 2019). Support for this can be found in the McKenzie reports (Mourshed \& Barber, 2007). indicated that high-quality academic teachers are needed to enable the education system to march forward and adapt to an era of changes and progress. A basic assumption of the McKenzie reports (Mourshed \& Barber, 2007) reports is that the education system's improvement is a long multi-stage journey, primarily including enhancement and establishment of a more appropriate system of teaching and management. Reports by the National Bureau of Statistics and the OECD (Ben Shabo, 2016) suggest that the percentage of dropout by teachers from the education system who are well versed in the field of content and trained to teach according to a continuous model (bachelor's degree in content and a teaching certificate) is relatively low compared with those who were trained according to an integrated model (a degree including teaching training for an M.Teach degree (Gil et al., 2019).

\section{Literature Review}

The teaching profession needs to improve the existing teacher training programs to adapt them to contemporary professional demands in order to ensure an appropriate academic level and to reinforce teaching staff. In order to attract high-quality candidates to teaching, from various academic backgrounds, new programs should be designed to make teaching a more attractive and lucrative profession. 
The coherence of teacher training programs is derived from the clarity of the different program components, such as goals and theoretical and practical components. Moreover, a coherent teacher training program recognizes learners as complete persons, who have the potential to learn, who have the ability to cope with 21 st-century changes, and who aspire to shape a common future founded on the functional, emotional, and personal welfare of the individual-alongside a concern for general public welfare (Beck, 2014).

In the new M.Teach program that opened at 11 education colleges in Israel, the learning format combined studies for a master's degree in teaching with studies for a teaching certificate for secondary schools. This is a new learning format in the teacher training system in Israel. Similar programs have been employed in many countries, following a growing trend within educational systems (Malik, 2018). The program's purpose is to highlight the importance of the teaching profession in order to attract high-quality candidates, from various academic backgrounds, who are professionally able and socially aware and to improve the working conditions of novice teachers who have already achieved an academic training in their content subject. The target population in Israel includes academics with a first degree in one of the disciplines studied in academic teacher-training institutions for secondary schools such as mathematics, biology, Land of Israel studies, Judaism, linguistics, or English. Israel has a complex multicultural society, this means that it is imperative that the teachers in the educational institutions are able to be culturally aware and sensitive. The M.Teach program is therefore designed to enable a broader understanding of social processes that influence the development of Israeli society in the 21st century. As noted teacher training studies are integrated within the degree studies throughout the entire study period, so that graduates receive an M.Teach certificate and a teaching certificate authorizing them to teach in their chosen profession in secondary schools.

The M.Teach program is adapted to guidelines for the learning of teaching, as in any teacher training program in any academic setting recognized by the Council for Higher Education. Additionally, the programs also comply with the conditions and principles determined by the Israeli Council for Graduate programs The program offers expanded and deepened studies in different fields and emphasizes the development of knowledge, understanding of theoretical research, and practical knowledge and understanding. The areas of expanded knowledge include innovative pedagogy and leadership in education. Two of the central aims of the program are to help the students to develop profound educational values and to encourage them to feel comfortable in applying innovative pedagogic principles in the school curriculum. The learner is perceived as an individual, who understand the influences of various trends in the philosophy, society, politics, communications, and the culture of education, addressing the significance of high-level morality and ethics in organizational and managerial culture, the influence of human motivation and empowerment, and fostering the ability to foster leadership and teamwork.

The program is dedicated to developing educational leadership able to strengthen multiculturalism in Israeli society. To ensure that future teachers are able to provide suitable levels of teaching and leadership in schools, their disciplinary knowledge should be integrated with multifaceted understanding and skills, such as innovative teaching, use of technology-assisted teaching, leadership in schools, and awareness of new research in neuro-pedagogy. These different disciplinary and advanced learning program components of the program are integral parts of the program in addition to basic courses in education.

In Israeli teacher training colleges, innovative pedagogy including various techno-pedagogic, pedagogic, and design aspects is a mandatory built-in part of the general curriculum for student-teachers. The colleges have innovative learning spaces in addition to simulation centers. The innovative centers operate in order to help students to try and to assimilate techno-pedagogic innovations, such as virtual reality and development of higher-order thinking. These unique teaching spaces and technological possibilities are used in innovative pedagogic research and in the development of various means of evaluation. This variety enables students to be exposed to and experiment in practice with varied advanced teaching strategies to promote meaningful and innovative learning. The teacher training colleges envisage their graduates becoming future education leaders, able to integrate within the state's education systems and guide them (Snoek, 2021).

In the Mteach program, learning of the methods and pedagogy of the teaching discipline and the practicum experience are all adapted to the discipline in which the student studies for their teaching certificate. In the first year, the practicum and the didactic lessons focus on the discipline; in the second year, students learn how to integrate innovative pedagogy and how to use technology in the teaching of their discipline.

The M.Teach program aims to equip future teachers with the skills necessary to lead the education system and develop their professional identity. The course enables the teacher to acquire knowledge, skills, and abilities, which serve as tools to address and adapt to an ever-changing environment. During their professional lives, the teachers accumulate professional insights and experiences that accompany them over the years, while they are 
teaching and leading education. The development process of a teaching employee is complex and continuous. The course emphasizes the personal and professional development of the trainee teacher, in the contexts of interpersonal and group processes.

To summarize: At the personal level, the program's shared vision represents the image of the "good teacher" as perceived by staff members, the desired quality of teaching and its future role in the education system. In recent decades, there is a growing demand to adapt the learning and teaching to the characteristics of the 21 st century (Hammerness, 2013). Coherent training programs help construct the professional identity of teachers, contribute to their sense of self-efficacy, and increase their self-confidence so that they can enter the teaching field with appropriate tools to cope with a rapidly changing reality.

\subsection{The Purposes of Teacher Training}

- To increase students' personal and professional ability to advance the achievements required when implementing their duties.

- To enable students to observe themselves and others through personal and interpersonal processes.

- To enable students to understand the essence of professional commitment and to develop it to ensure high-quality teaching and learning for students.

- To enable students to practice interpersonal interaction in a supportive and non-judgmental manner.

- To examine students' choice of the teaching profession in depth (their expectations, intrinsic, and extrinsic motivations).

Collaboration between academia and educational institutions such as schools strengthens the professional identity of both faculty members and student-teachers. Cooperation in the professional learning community enables students to overcome barriers to disciplinary expertise and expand their learning. Teacher training programs have been shown to influence the development of the trainees' professional identity, an example being the STEP program of Stanford University (Canrinus et al., 2017).

\subsection{The Image of the Future Graduate}

The future teacher needs both extensive disciplinary knowledge and teaching skills adapted to the global changes affecting the world's educational systems. These changes relate to paradigm shifts from local-standards-based systems to universal-standards-based systems, from closed systems to interactive and collaborative systems, and from systems based on uniformity to systems that focus on diversity. Hence, the educational act is currently constantly altering its appearance. Personal reflection and group reflection help trainees focus on emotional and structural aspects as they develop their professional identity, and especially when they try to integrate the theoretical knowledge, they have gained with the practical knowledge gained on entry to the teaching profession (Allen et al., 2018). This professional expertise is known as "flexible expertise" in the language of teacher training programs (Kuzminski, 2008). The use of innovative pedagogy and the integration of technology in teaching are key milestones in the training of future teachers. These transitions to the digital age and changes in paradigms in the field of education affect teachers' character and characteristics and the teaching-learning process.

In the 21st century, in addition to profound disciplinary knowledge, teachers are expected to master new skills and technologies. They need to recognize different types of media such as the Internet and various applications, to master them well, to know a variety of digital tools for online learning and teaching, and to integrate them in their educational work.

Additionally, teachers should be able to think reflectively and meta-reflectively, which will allow them to adapt to react flexibly and adapt to alterations in the teaching field and to changing situations. As noted, in recent decades, education systems around the world have been required to adapt to changes in life and its conditions. Adjustments include moving from focusing on learning in the learning process to focusing on applying knowledge in new situations, developing critical thinking skills for both students and teachers, improving interpersonal communication skills, encouraging creative thinking, developing collaborative skills and creating collaborations, and developing lifelong learning opportunities.

This reality affects the field of teaching and the field of teacher training in many ways (Darling-Hammond et al., 2017) so that it is oriented to helping student-teachers to use these skills and develop creative and flexible thinking that adapts to future changes and simultaneously guides them. For this and other reasons, the M.Teach program also emphasizes various aspects of educational leadership. Rogers (2011) wrote that incoherence in a training program can cause insecurity for teaching trainees and undermine their professional identity. Lack of 
alignment between training programs and the public's goals or requirements and the needs of the economy and society has been described as an obstacle to promoting systemic, social, and cultural changes (Chan, 2010).

A graduate of the M.Teach program in the digital age will have mastered four aspects of information and communications technology (ICT): technological literacy, use of ICT for academic purposes, use of ICT for teaching purposes, and understanding its value within the framework of professional practice. Future teachers will operate in a dynamic digital culture; thus, it is insufficient to train them merely to use the technologies in the schools: they will also need to know how to adapt teaching content and learning methods to advanced technologies even if these are not yet integrated in schools. This is because the expectation is that they will be found in the education system in the next few years. The vision for teacher training is based on setting standards for the required skills and attitudes needed for the profession as well as professional standards designed to guide teaching practice (Darling-Hammond et al., 2017). It is therefore important that graduates from the M.Teach program are steeped in innovative technologies, which will occupy a central place in their own and their future students' teaching and learning. However, it is also important that future graduates of the program be able to combine technological advancement with the pedagogical and emotional aspects of learning and be able to adapt values of teaching appropriately to meet social changes (see Figure 1).
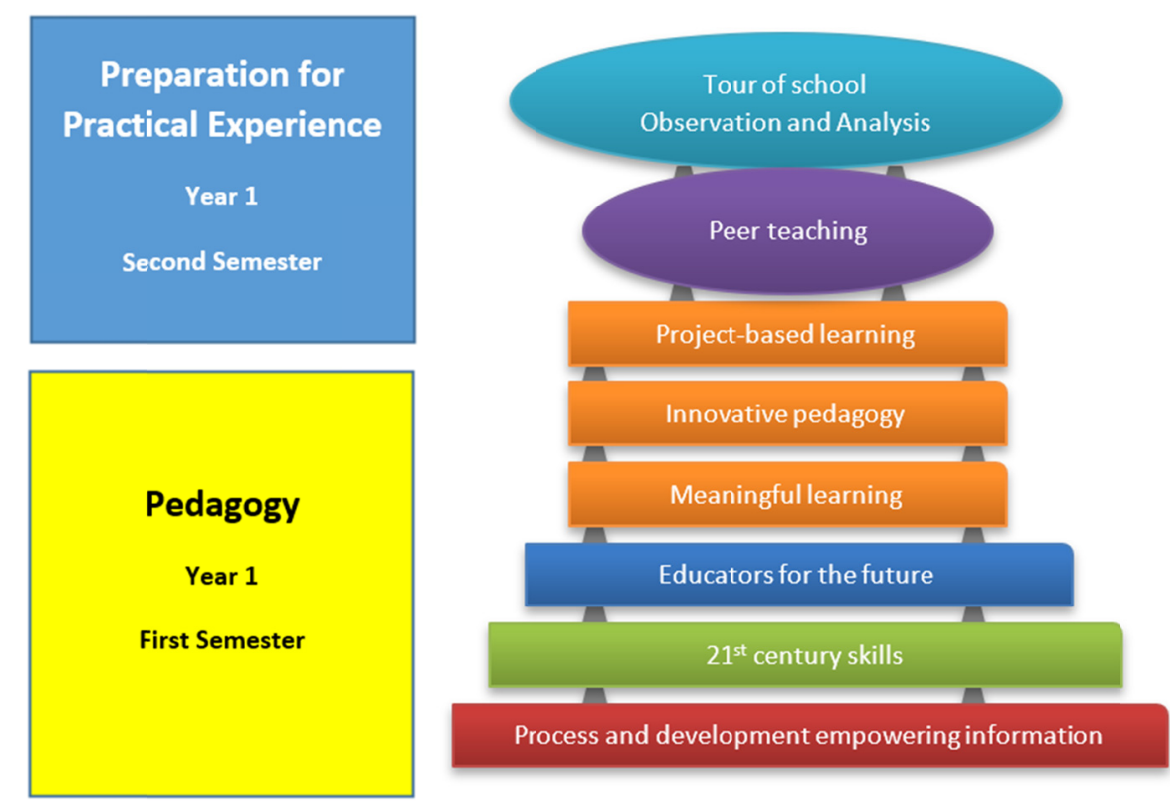

Figure 1. The Components of teacher training

Note. From Simon et al., 2014.

\subsection{The Purpose of the Research}

The research described here examined the development of future teachers' professional identity and characteristics by investigating the attitudes and perceptions of student-teachers currently undergoing training processes or approaching the end of their studies for the M.Teach degree concerning the image of the future teacher.

\section{The Research Method}

\subsection{The Research Tools}

A questionnaire included two parts: (a) socio-demographic data, and (b) the Professional Identity Questionnaire developed by Fisherman and Weiss (2011) investigating teachers' professional identity, which respondents were asked to grade on a Likert scale of 1 to 4 . The questionnaire included 43 statements that students graded on a Likert scale from 1 (very incorrect) to 4 (very correct). The last two items were adapted to examine the COVID-19 pandemic era. The statements were divided into four dimensions. The respondents' rankings for the statements underwent quantitative analysis. 


\subsection{The Research Questions}

1) How is the figure of the future teacher portrayed in the eyes of M.Teach program trainees?

2) What in their opinion is the desired character for the future teacher?

3) Is there a difference between their perception of the 'future teacher', and their perception of the concept of "teacher"?

4) Is it possible to identify a central pattern that emerges from the analysis of all the answers and statements?

\subsection{The Research Population}

The questionnaire was administered at the beginning of the 2019-2020 academic year to 28 students in the M.Teach program, five did not respond, so that the research relates to the responses of 23 students.

\subsection{The Research Process}

The questionnaire was administered to the group of students in Years 1 and 2 of the learning program for the M.Teach degree at a single teacher training college. Responses were given anonymously.

\section{Findings}

\subsection{Socio-demographic Qualities of the Participants}

Twenty-three students from the M.Teach program responded to the questionnaire. Most were women $(\mathrm{n}=21$, $91.3 \%)$, and most were in the 20-30 age group $(\mathrm{n}=14,60.9 \%)$. The remaining students were in the $31-40(\mathrm{n}=4$, $17.4 \%)$ and $41-50(\mathrm{n}=4,17.4 \%)$ age groups, and one was over $50(4.3 \%)$. The disciplinary specializations of the students were mathematics $(\mathrm{n}=8,34.8 \%)$, biology $(\mathrm{n}=8,34.8 \%)$, language $(\mathrm{n}=3,13.0 \%)$, Land of Israel studies $(\mathrm{n}=2,8.7 \%)$, and Judaism $(\mathrm{n}=2,8.7 \%)$.

\subsection{Findings from the Professional Identity Questionnaire (Fisherman \& Weiss, 2011)}

Explorative and confirmatory factor analysis (Fisherman \& Weiss, 2011) found four factors in the questionnaire: (1) confidence concerning the choice of profession, (2) self-efficacy in teaching, (3) a sense of mission, (4) the reputation of teaching.

The questionnaire was found to have normal to good internal consistency: (1) confidence concerning the choice of profession: $\alpha=0.87$; (2) self-efficacy in teaching: $\alpha=0.87$, (3) a sense of mission: $\alpha=0.66$, and (4) the reputation of teaching: $\alpha=0.64$. The correlation between the two items addressing the outbreak of the COVID-19 pandemic ("Corona makes me more creative," "the Corona period strengthens the teacher's status") was found to be $r=0.58(p=0.004)$. The subscales were defined according to the mean of their items and the total grade was defined $(\alpha=0.90)$. A higher grade represents a more positive/consolidated professional identity.

Table 1 displays the means, standard deviations, and correlations for the research variables. The data in the table show that very high means were found for the dimensions of professional identity, ranging from 1 to 4 . Of the original dimensions of the questionnaire, the mean grade for self-efficacy in teaching was highest (3.42), and the mean grade for teaching's reputation, was lowest (3.00). However, the mean grade for professional identity in the context of the COVID-19 pandemic was lowest of all (2.83). The difference between the means was found to be significant, $F(4,88)=5.40, p=0.022, \eta^{2}=0.197$.

Table 1. Means, standard eeviations, and correlations for the research variables $(\mathrm{N}=23)$

\begin{tabular}{lllllll}
\hline Dimension & Mean $(S D)$ & Self-efficacy & $\begin{array}{l}\text { Sense of } \\
\text { mission }\end{array}$ & $\begin{array}{l}\text { Reputation of } \\
\text { teaching }\end{array}$ & $\begin{array}{l}\text { Identity during } \\
\text { COVID-19 }\end{array}$ & $\begin{array}{l}\text { Identity total } \\
\text { score }\end{array}$ \\
\hline Confidence in choice of profession & $3.25(0.41)$ & $0.79^{* * *}$ & $.57^{* *}$ & $.45^{*}$ & .12 & $.90^{* * *}$ \\
Self-efficacy in teaching & $3.42(0.39)$ & & $.38(1)$ & $.36(1)$ & -.17 & $.77^{* * *}$ \\
A sense of mission & $3.21(0.54)$ & & $.56^{* *}$ & .14 & $.76^{* * *}$ \\
The reputation of teaching & $3.00(0.69)$ & & & .21 & $.70^{* * *}$ \\
Professional identity in the context of & $2.83(0.72)$ & & & .19 \\
COVID-19 & & & & \\
Professional identity-total score & $3.19(0.34)$ & & & \\
\hline Note. Range $=1-4 ;{ }^{(1)} \mathrm{p}<.10,{ }^{*} \mathrm{p}<.05,{ }^{* *} \mathrm{p}<.01, * * * \mathrm{p}<.001$. & & &
\end{tabular}

As shown in the table, positive correlations were found of a medium to high strength between the original questionnaire dimensions. In other words, positive correlations were found between stronger confidence in the choice of the profession, strong self-efficacy in teaching, a higher sense of mission, and better reputation of 
teaching. No significant correlations were found between these dimensions and the total grade and professional identity in the context of the COVID-19 pandemic.

Results of an examination of the dimensions of professional identity according to the age of the participants are presented in Table 2. For the purposes of comparison, the participants were grouped in two groups as ages 20 to 30 years $(n=14,60.9 \%)$ and age 31 years and older $(n=9,39.1 \%)$. As the table shows, in general the scores for the dimensions of professional identity are higher for the younger group, except for identity in the context of the COVID-19 epidemic. This difference was significant for self-efficacy in teaching and borderline for the overall score for professional identity.

Table 2. Results for the dimensions of professional identity, by respondents' age group $(\mathrm{N}=23)$

\begin{tabular}{llll}
\hline Dimension & Age 21-30 years & Age 31+ years & $\begin{array}{l}\text { Difference } \\
\mathbf{Z}\end{array}$ \\
\hline Confidence in choice of profession & Mean $(S D)$ & Mean $(S D)$ & 0.73 \\
Self-efficacy in teaching & $3.30(0.45)$ & $3.19(0.33)$ & $2.28^{*}$ \\
A sense of mission & $3.56(0.35)$ & $3.21(0.37)$ & 0.35 \\
The reputation of teaching & $3.25(0.63)$ & $3.14(0.40)$ & 0.70 \\
Professional identity in the context of COVID-19 & $3.12(0.53)$ & $2.81(0.88)$ & 0.61 \\
Professional identity-total score & $2.79(0.51)$ & $2.89(0.99)$ & $1.64(1)$ \\
\hline
\end{tabular}

Note. ${ }^{(1)} \mathrm{p}<.10,{ }^{*} \mathrm{p}<.05, * * \mathrm{p}<.01, * * * \mathrm{p}<.001$.

No differences emerged for the dimensions of the students' professional identity according to their disciplinary specialization, both when divided into three groups (mathematics/biology/other) and when divided into two groups (mathematics and biology/other; "other" includes Hebrew language, the Land of Israel, and Judaism).

\section{Limitations of the Study}

The questionnaire was a static questionnaire. It examined the professional identity of students during their training process as part of the M.Teach degree program at a given moment and at one teacher training college. The questionnaire was not sensitive to a continuous developmental process over time, and it does not describe a personal narrative story and/or interpretation.

\section{Discussion}

The research aimed to examine the meaning of the term "teachers' professional identity" as expressed by students studying toward the M.Teach degree. Based on students' answers to the research questionnaire and according to the factor analysis, teachers' professional identity can be defined as teachers' thoughts and feelings about their professional choice, their professional realization, their sense of mission, and their feelings about the reputation of teaching, especially in light of their choice of studies for a master's degree that combines both academic teaching studies and a teaching certificate.

The first factor is the teacher's confidence in their choice of the teaching profession. Positive associations were found between stronger confidence in professional choice, greater self-confidence in teaching, a higher sense of mission, and a better reputation for teaching. Specifically, a teacher who is confident in their professional choice enters the classroom out of a sense that even though they may have other professional alternatives, they have chosen teaching as a desirable and worthy option. This type of teacher will perceive their professional identity as consolidated. On the other hand, there is a risk that a teacher who is unsure of their choice of teaching but continues to teach will soon experience burnout.

The second factor, teacher's sense of self-efficacy, refers to the teacher's feeling that they are capable of being a good teacher. A strong sense of self-fulfillment means the teacher feels that they have the qualities and skills to be a good teacher. The research found positive correlations, medium to high in intensity, between the dimensions of the original questionnaire: positive associations were found between stronger confidence in professional choice, greater self-fulfillment in teaching, a greater sense of mission, and a stronger reputation for teaching. It seems that a teacher who is confident in their abilities, knowledge, and skills possesses a more cohesive professional identity. A teacher who fears that they lack some of the conditions necessary to be a good teacher and who still continues to teach possesses a more diffuse professional identity, and there is a strong risk of dropout from the profession (Isotalo, 2017).

The third factor is the teacher's sense of mission. This factor is mentioned by Roby (2009) discussing the link between the teacher's sense of mission and their contribution to the school. Note that the questionnaire 
developed for this study did not address the content of the mission but instead related to the teacher's subjective sense of having a mission, including the sense that they are responsible and supported by someone who has sent them. Although the sense of mission relates to the present, it also relates to the future. If I am sent on a mission, then I need to fulfill that mission in the near or distant future. There is a connection between the sense of mission and the sense of self-efficacy: I am on a mission and I can fulfill that mission. We believe that while a sense of confidence in the choice of profession and sense of professional efficacy are related to the teacher's feelings about themselves, sense of mission also refers to the teacher's external world because the teacher feels that they are a messenger for someone: a society, an ideal, a metaphysical factor, their students, and so forth. These important questions - such as "who am I a messenger for, for what, and for which goals?" should form questions for future research employing suitable research methods.

The fourth factor is the reputation of education and teaching. This factor seems to echo the concepts of Moore (1970), who emphasized that teaching needed social appreciation to reinforce professional identity. Similarly, Tickle (1999) argued that professional identity is a combination of how teachers see themselves and how society sees teachers. Aloni (2009) pointed to the deterioration of the reputation of teaching and its implications. Farber (1991) argued that the sizable deterioration of teachers' professional image makes it possible to speak of the "de-professionalization" of teaching. Avishar and Dvir (2009) claimed that the teaching profession has become the scapegoat for all of society's ills. Cohen and colleagues (1999) succinctly described an opposite trend: that if teaching has become the scapegoat, it can also be the remedy, because education and teaching are expected to cure society of its ills. Of course, if this is so, why do teacher educators and teachers need to point to their profession's reputation as a factor in their professional identity?

\section{Conclusions}

This paper addresses the initial viewpoint of students studying for a master's degree in teaching and a teaching certificate. The students' profile was characterized by relatively high ages for teaching students studying for a master's degree. The students were also characterized by the fact that choosing to be a teacher was not their first choice in their professional development in the labor market and they came to the teaching profession after testing themselves in the labor market. It would be informative to reexamine this type of population in the future after they have completed five years of fieldwork as teachers and see how that work has affected their professional identity and what they felt were the best tools that led them to continue to work in the teaching profession. A combination of knowledge about teacher identity and their professional development could help inform future teacher training processes.

\section{References}

Allen, K. L., Brodeur, K., Israelson, M. H., Martin-Kerr, K. G., Ortmann, L., \& Peterson, D. S. (2018). Developing reflective practice in teacher candidates through program coherence. Teaching \& Learning Inquiry, 6(2), 81-96. https://doi.org/10.20343/teachlearninqu.6.2.7

Aloni, N. (2009). Empowering dialogues in education. Kibbutz Hameuchad [Hebrew].

Avishar, A., \& Dvir, N. (2009). Academics applying for teaching-What motivates them? A comparative study between men and women. Tel Aviv: Kibbutzim Seminar College [Hebrew].

Beck, S. (2014). For (J) teacher training - A philosophical perspective on teacher training. Tel Aviv: Mofet [Hebrew].

Ben, S. R. (2016). Trends in the development of education system in Israel. Free International University of Moldova, Israel. Retrieved from https://www.elibrary.ru/item.asp?id=42765344

Canrinus, E. T., Bergem, O. K., Klette, K., \& Hammerness, K. (2017). Coherent teacher education programmes: Taking a student perspective. Journal of Curriculum Studies, 49(3), 313-333. https://doi.org/10.1080/00220272.2015.1124145

Chan, J. K. S. (2010). Teachers' responses to curriculum policy implementation: Colonial constraints for curriculum reform. Educational Research for Policy and Practice, 9(2), 93-106. https://doi.org/10.1007/s10671-010-9082-5

Cohen, L. M., Higgins, K. M., \& Ambrose, D. (1999). Educators under siege: The killing of the teaching profession. The Educational Forum, 63(2), 127-137. https://doi.org/10.1080/00131729908984403

Darling-Hammond, L., Burns, D., Campbell, C., Goodwin, A. L., Hammerness, K., Low, E. L., ... Zeichner, K. (2017). Empowered educators: How high-performing systems shape teaching quality around the world. Wiley. 
Dovrat Committee recommendations. (2004). The national program for education in Israel. Jerusalem: Prime Minister's Office. Retrieved from https://www.gov.il/he/departments/policies/2005_des3060 [Hebrew].

Farber, B. A. (1991). Crisis in education: Stress and burnout in the American teacher. Jossey-Bass.

Fisherman, S., \& Weiss, J. (2011). Professional identity of teachers: The concept and its measurement. Dapim, 51, 39-56. Mofet. Tel-Aviv [Hebrew].

Gil, A. J., Antelm-Lanzat, A. M., Cacheiro-González, M. L., \& Pérez-Navío, E. (2019). School dropout factors: a teacher and school manager perspective. Educational Studies, 45(6), 756-770. https://doi.org/10.1080/03055698.2018.1516632

Hammerness, K. (2013). Examining features of teacher education in Norway. Scandinavian Journal of Educational Research, 57(4), 400-419. https://doi.org/10.1080/00313831.2012.656285

Isotalo, S. (2017). Teacher educators' professional identity formation in a challenging context: Experience from Eritrea. Master's thesis, University of Jyväskylä, Finland.

Kuzminski, L. (2008). Professional identity in teaching, research paths. In Yearbook No. 15. Tel Aviv: Mofet. [Hebrew]

Malik, R. S. (2018). Educational challenges in 21st century and sustainable development. Journal of Sustainable Development Education and Research, 2(1), 9-20. https://doi.org/10.17509/jsder.v2i1.12266

Moore, W. E. (1970). The professions: Roles and rules. New York: Russell Sage Foundation. Retrieved from https://www.russellsage.org/sites/default/files/Professions.pdf

Mourshed, M., \& Barber, M. (2007). How the world's best performing school systems come out on top. McKinsey \& Co. Retrieved from https://www.mckinsey.com/ /media/mckinsey/industries/public\%20and\%20social\%20sector/our\%20insigh ts $/$ how $\% 20$ the $\% 20$ worlds $\% 20$ best $\% 20$ performing $\% 20$ school $\% 20$ systems $\% 20$ come $\% 20$ out $\% 20$ on $\% 20$ top $/ \mathrm{h}$ ow_the_world_s_best-performing_school_systems_come_out_on_top.pdf

Richmond, G., Bartell, T., Carter Andrews, D. J., \& Neville, M. L. (2019). Reexamining coherence in teacher education. Journal of Teacher Education, 70(3), 188-191. https://doi.org/10.1177/0022487119838230

Roby, D. E. (2009). Teacher perceptions of levels of professional contribution to the school. College Student Journal, 43(3).

Rogers, G. (2011). Learning-to-learn and learning - to - teach: The impact of disciplinary subject study on student-teachers' professional identity. Journal of Curriculum Studies, 43(2), 249-268. https://doi.org/10.1080/00220272.2010.521262

Simon, E., Neifeld, E., \& Levine, N. (2014). Teacher training in Year 1 of the elementary stream in Ohalo Academic College (pp. 90-93). Tel Aviv: Bimat Diun. [Hebrew]

Snoek, M. (2021). Educating quality teachers: How teacher quality is understood in the Netherlands and its implications for teacher education. European Journal of Teacher Education, 1-19. https://doi.org/10.1080/02619768.2021.1931111

Tickle, L. (1999). Teacher self-appraisal and appraisal of self. In R. P. Lipka \& T. M. Brinthaupt (Eds.), The role of self in teacher development (pp. 121-141). NY: State University of New York Press.

\section{Copyrights}

Copyright for this article is retained by the author, with first publication rights granted to the journal.

This is an open-access article distributed under the terms and conditions of the Creative Commons Attribution license (http://creativecommons.org/licenses/by/4.0/). 